DOI: 10.1002/adma.((please add manuscript number))

\title{
Assembly of free-standing polypeptide films via the synergistic combination of hyperbranched macroinitiators, the grafting-from approach and cross-chain termination.
}

By Steven Harris Wibowo, Edgar H. H. Wong, Adrian Sulistio, Stefanie N. Guntari, Anton Blencowe, Frank Caruso, ${ }^{*}$ and Greg G. Qiao*

[*] Department of Chemical and Biomolecular Engineering

The University of Melbourne

Parkville, VIC 3010, Australia

Email: greghq@unimelb.edu.au,fcaruso@unimelb.edu.au

Keywords: surface-initiated polymerisation, cross-linked capsules, polypeptide, biodegradable, $\mathrm{N}$-carboxyanhydrides, ring-opening polymerisation

Synthetic peptide-based materials with various macromolecular architectures are of interest because of their tuneable functionalities, conformations and specific stereochemistries, as well as their biocompatibility and (bio)degradability, which makes them desirable for nano(bio)technology applications, especially in polymer therapeutics. ${ }^{[1-7]}$ In particular, hollow polymeric capsules (i.e., coreless free-standing cross-linked films capable of cargo encapsulation) comprised of amino acid constituents would be attractive as biomolecular devices. ${ }^{[8]}$ To date, the fabrication of peptide-based capsules have utilised techniques driven by self-assembly, such as the layer-by-layer (LbL) deposition of charged biopolymers. ${ }^{[5,8-14]}$ Alternatively, the formation of degradable peptide-based cross-linked capsules has also been achieved by the polymerisation of dopamine-modified polypeptide chains. ${ }^{[13]}$ Although these approaches allow for fine control over the capsule film properties, the synthesis of prefunctionalised polypeptides (or proteins) and subsequent film generation often involves multistep processing and/or synthesis. On the other hand, the surface grafting approach has also been utilised to fabricate polypeptide films on various substrates such as silicon wafers, silica particles, and more recently, magnetite nanoparticles with defined composition and secondary 
e, drug/protein conjugation and surface modification. ${ }^{[6,7,15-27]}$ However, despite the demonstrated robustness and versatility, the lack of film cross-linking prevents the formation of free-standing coreless polypeptide capsules. Thus, given the numerous beneficial properties of polypeptide coatings and free-standing films, and the current synthetic limitations, it was the aim of this study to report the facile preparation of cross-linked polypeptide capsules by a new and versatile approach driven by surface-initiated polymerisation with simultaneous in situ cross-linking mediated by crosschain termination reaction.

The intermolecular termination of growing polypeptide chains during ring-opening polymerisation (ROP) of amino acid $N$-carboxyanhydride (NCA) in solution is a recently observed phenomenon. In 2010, Heise and co-workers have reported the occurrence of sidereactions during amino acid NCA-ROP which leads to the formation of 'dead' polymer chains as a result of intramolecular cyclisation. ${ }^{[28]}$ For example, the ROP of benzyl-L-glutamate NCA in solution at $20{ }^{\circ} \mathrm{C}$ results in the formation of poly(benzyl-L-glutamate) (PBLG) with a substantial fraction of chains terminated by pyroglutamate groups as a result of intramolecular cyclisation of the propagating amine end-group with the adjacent side-chain benzyl ester protecting group.

Based upon these reports we hypothesised that it should be possible to exploit this sidereaction as a cross-linking mechanism to form free-standing nanoscale polypeptide films in a single-step using the judicious combination of hyperbranched macroinitiators, surface initiated ROP of $\alpha$-amino acid NCA derivatives (grafting-from approach) and cross-chain termination reactions. Whereas the hyperbranched macroinitiators provide an intertwined mesh at the base of the film from which the polypeptide grafts extend, the cross-chain termination reactions serve to interlock the grafted chains in place. To demonstrate this 
principle, we carried out a study of the facile formation of stable and free-standing polypeptide capsules with tuneable properties via the ROP of amino acid NCA monomers having labile benzyl ester protecting groups (e.g., benzyl-L-glutamate $N$-carboxyanhydride (Glu-NCA)) using hyperbranched poly(ethylene imine) (PEI) macroinitiators deposited on colloidal silica templates, followed by deprotection and template dissolution. The macroinitiators initiate the ROP of Glu-NCA to generate highly dense polypeptide brush films leading to promote cross-chain termination reactions between the propagating amine endgroups of the growing polymer brushes and the side-chain benzyl ester protecting groups from neighbouring polymer chains, thereby generating stable cross-linked polypeptide films in a single-step (Scheme 1).

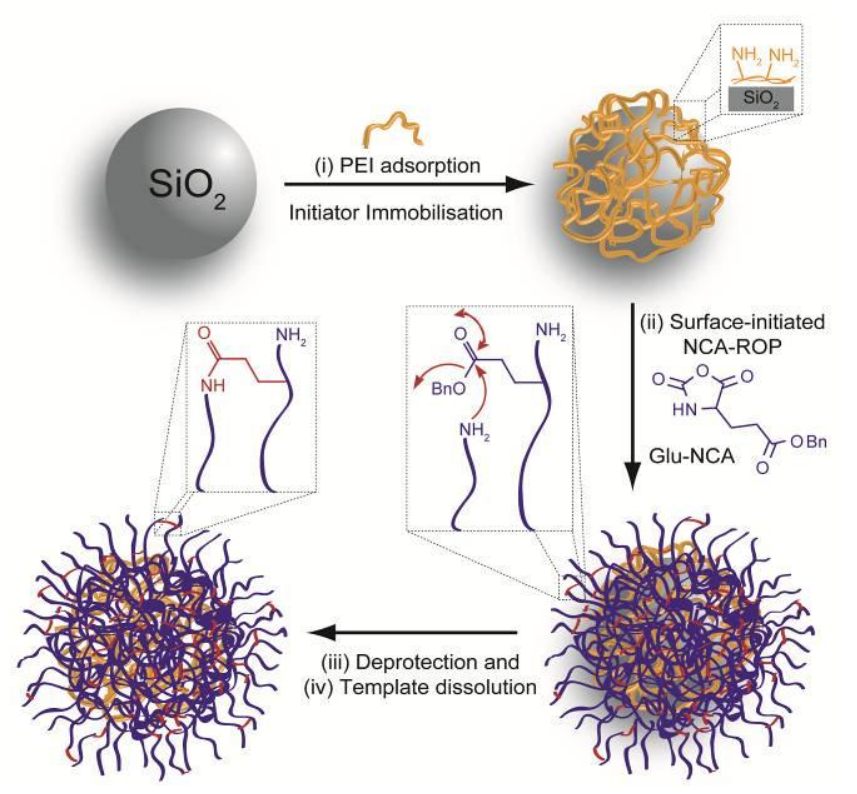

Scheme 1. Fabrication of stable poly(L-glutamic acid) (PLGA) capsules: (i) Deposition of poly(ethylene imine) (PEI) macroinitiator on silica ( $5.0 \pm 0.2 \mu \mathrm{m}$ diameter) templates followed by (ii) surface-initiated ROP of benzylL-glutamate NCA (Glu-NCA), (iii) deprotection of the remaining benzyl ester protecting groups with $\mathrm{HBr}$ and (iv) template dissolution using buffered $\mathrm{HF} / \mathrm{NH}_{4} \mathrm{~F}$ solution.

Specifically, silica particles $(5.0 \pm 0.2 \mu \mathrm{m})$ were functionalised with PEI macroinitiators through electrostatic interactions to introduce free amine groups on the silica surface. These amine groups were then employed to initiate the ROP of Glu-NCA from the surface of the silica templates to generate poly(benzyl-L-glutamate) (PBLG) grafts (Scheme 1). After 


\section{Submitted to

polymerisation, the remaining benzyl ester protecting groups on the PBLG grafts were deprotected using $\mathrm{HBr}$ to afford poly(L-glutamic acid) (PLGA) grafts. Subsequently, the silica templates were dissolved using $\mathrm{HF} / \mathrm{NH}_{4} \mathrm{~F}$ solution (pH 5.0) (refer to Supplementary Information (SI)) to afford stable and dispersible, hollow PLGA capsules.
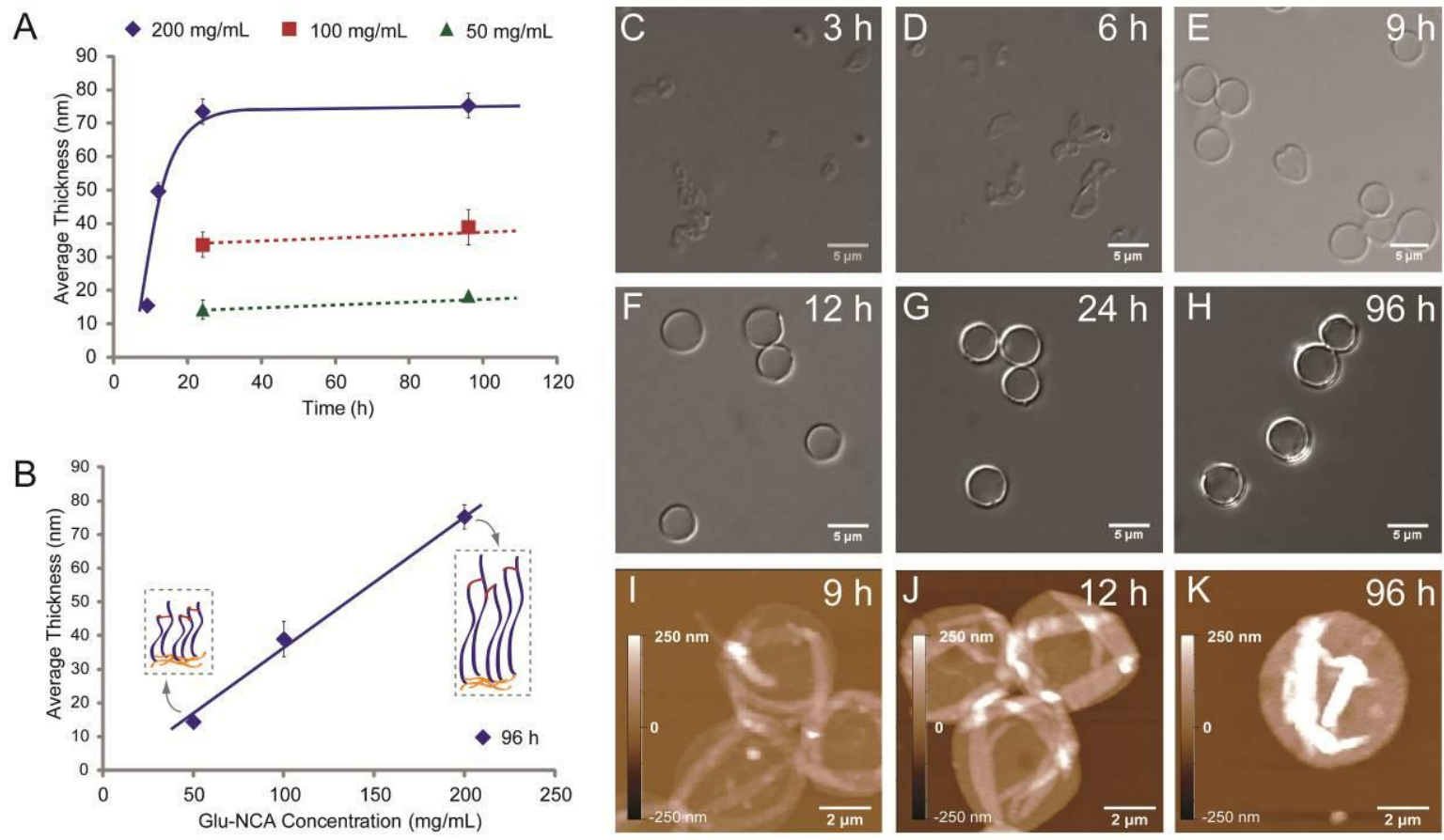

Figure 1. Evolution of PLGA capsule wall thicknesses as a function of (A) polymerisation time (using an initial Glu-NCA concentration of 50, 100 and $200 \mathrm{mg} / \mathrm{mL}$ ) and (B) initial monomer concentration after polymerisation times of 96 h. DIC microscopy images of PGA capsules formed after (C) 3, (D) 6, (E) 9, (F) 12, (G) 24 and (H) $96 \mathrm{~h}$ of polymerisation (using an initial Glu-NCA concentration of $200 \mathrm{mg} / \mathrm{mL}$ ), deprotection and template dissolution. AFM images of air-dried PGA capsules formed after (I) 9, (J) 12 and (K) 96 h of polymerisation, deprotection and template dissolution. Scale bars for DIC microscopy and AFM images are 5 and $2 \mu \mathrm{m}$, respectively.

To study the growth profile of the films over time, the wall thickness of the resulting capsules (isolated after template removal) was measured after the polymerisation was terminated at different time intervals (Figure 1A, $200 \mathrm{mg} / \mathrm{mL}$ initial Glu-NCA concentration) by isolating the particles from the Glu-NCA monomer solution. Notably, no stable capsules were formed when the polymerization was terminated at 3 and $6 \mathrm{~h}$, as confirmed by differential interference contrast (DIC) microscopy images (Figure 1C-D), which revealed 
h onwards stable PLGA capsules were

only deformed remnants of capsules. However, from $9 \mathrm{~h}$ onwards stable PLGA capsules were formed as observed from DIC microscopy (Figure 1E-H) and atomic force microscopy (AFM) (Figure 1I-K) images. The wall thickness of the air-dried capsules, as measured by atomic force microscopy (AFM), revealed a steady increase between 9 and $24 \mathrm{~h}$, after which the wall thickness plateaus (Figure 1A), indicating the lack of polymer growth after $24 \mathrm{~h}$. Height-profile AFM analysis of the dried capsules ( $\mathrm{n}>10$ for each time point) provided single-wall thicknesses ranging from $16 \pm 1.5 \mathrm{~nm}$ after $9 \mathrm{~h}$ to a maximum of $75 \pm 3.7 \mathrm{~nm}$ at 96 h (Figure 1A). Not only does this demonstrate that stable capsules can be formed with relatively short grafts, but also that the capsule film thicknesses are tuneable (16 to $75 \mathrm{~nm}$ ) by varying the polymerisation time.

Similarly, kinetic study was also performed with initial Glu-NCA concentration of 20, 50 and $100 \mathrm{mg} / \mathrm{mL}$. When the polymerisation was conducted with an initial Glu-NCA concentration of $20 \mathrm{mg} / \mathrm{mL}$, only collapsed capsules were observed by DIC microscopy and they were unstable for AFM analysis. Meanwhile at initial Glu-NCA concentrations of 50 and $100 \mathrm{mg} / \mathrm{mL}$, stable capsules were obtained only after $24 \mathrm{~h}$ polymerisation. For these concentrations, height-profile AFM analysis determines the average capsule wall thicknesses to be $14 \pm 0.6$ and $39 \pm 5.3 \mathrm{~nm}$ respectively (96 h polymerisation) (Figure 1A). Notably, the final capsule thicknesses were found to be linearly dependent on the initial monomer concentration (Figure 1B), indicating the dependence of polymer grafting rate onto initial monomer concentration. This is consistent with the results previously observed in literature. [27] The morphologies of the capsules also appear to improve with increasing monomer concentration (refer to Supporting Information (SI), Figure S1). Interestingly, capsules analysed after $24 \mathrm{~h}$ of polymerisation at various Glu-NCA concentrations produced almost identical wall thicknesses and morphologies to those isolated after $96 \mathrm{~h}$ (Figure 1A). This suggests that at all initial Glu-NCA concentrations, the growth of capsule wall thickness 


\section{Submitted to

appears to level-off after similar polymerisation time (i.e. around $24 \mathrm{~h}$ ), indicating the significant occurrence of termination event. Since other polymerisation parameters (temperature, initiator density and silica particles concentration; refer to SI) were kept constant, it appears that the growth of peptide brush within the first $24 \mathrm{~h}$ is governed by the rate of propagation (higher propensity at higher monomer concentration). However, regardless of the initial monomer concentration, the capsule wall thicknesses level-off after 24 $\mathrm{h}$ as a result of constant rate of termination which resulted in the different final capsule thicknesses.

Since a large excess of monomer is used relative to silica particles it is unlikely that all of the monomer is consumed (confirmed by ${ }^{1} \mathrm{H}-\mathrm{NMR}$ of reaction supernatant, Figure S2), which would suggest that the inactivity of the propagating amine end-groups may be responsible for termination of the polymerisation. While physical burial of the amine end-groups within the film is plausible, it is more likely that a large proportion of the amine end-groups have undergone the proposed cross-chain termination, which inhibits the polymerisation process. Irrespective of the initial monomer concentration, it is anticipated that the amount of amine end-groups on the surface grafted polymers are gradually lost as a result of termination events, which ultimately results in the termination of film growth once all of the free amines have been consumed. For verification, PBLG-coated particles formed after $24 \mathrm{~h}$ (initial GluNCA concentration of $200 \mathrm{mg} / \mathrm{mL}$ ) were incubated in a fresh solution of Glu-NCA (200 $\mathrm{mg} / \mathrm{mL}$ ) for a further $24 \mathrm{~h}$ before deprotection with $\mathrm{HBr}$ and particle dissolution with $\mathrm{HF}$ solution. AFM analysis of the resulting PLGA capsules revealed a negligible increase of capsule wall thickness (from $65 \pm 5.5 \mathrm{~nm}$ to $68 \pm 2.1 \mathrm{~nm}$ ) after the chain extension with fresh Glu-NCA (Figure S3). This indicates the prominent loss of free amine end-groups as a result of termination reactions during the first ROP, which significantly reduces the available initiating sites for subsequent ROP reactions. 


\section{Submitted to \\ ADVANCED}

As observed previously in solution polymerisation, the occurrence of intramolecular cyclisation of the propagating amine end-groups during ROP of NCA derivatives with benzyl ester protecting groups (e.g., benzyl-L-glutamate NCA and benzyl-L-aspartate NCA) can result in terminated polymer chains. ${ }^{[28]}$ Here, for surface-bound dense films, it is conceivable that such termination reactions become significant, and that the propagating amine end-groups undergo cross-chain termination through nucleophilic attack at the carbonyl carbon of benzyl ester side-groups on adjacent polymer chains (Scheme 1), leading to the formation of inactive amide groups and the release of benzyl alcohol. Such cross-chain termination reactions would result in cross-linking of the grafted polymer chains and enhance the stability of the films. In theory, the benzyl alcohol generated during the cross-chain termination event can subsequently initiate ROP of the NCA monomer in solution, leading to the formation of free polymer chains. To confirm that multiple cross-chain terminations actually occur and hence facilitate the formation of stable capsules, the reaction solution isolated after $24 \mathrm{~h}$ of polymerisation (initial Glu-NCA concentration of $200 \mathrm{mg} / \mathrm{mL}$ ) was analysed via matrix assisted laser desorption ionisation time-of-flight mass spectrometry (MALDI ToF MS); if benzyl alcohol is generated and initiates ROP in solution there should be evidence of PBLG with benzyl end-groups. The mass spectrum of the reaction solution revealed multiple series of peaks, each with a repeat pattern corresponding to the benzyl-L-glutamate repeat unit (Figure S4). Analysis of the mass values enabled the end-groups of various PBLG chains to be determined and provided evidence of polymer chains initiated by benzyl alcohol (D1 to D3, Figure S4) in addition to others initiated from impurities (e.g., dimethyl amine) present in the solvent (DMF) (Figures S4 and S5). These results confirm that benzyl alcohol is generated during capsule formation, although it may originate from both intramolecular cyclisation of polymer chains in solution and cross-chain termination reactions of the grafted polymer chains. 


\section{Submitted to

To further validate that the PLGA films are cross-linked as a result of cross-chain termination reactions, the PLGA capsules isolated after $24 \mathrm{~h}$ of polymerisation using a GluNCA concentration of $200 \mathrm{mg} / \mathrm{mL}$ were incubated in a series of buffer solutions $(\mathrm{pH} 4.0,8.4$ and 11.0). The pendent carboxylic acid groups of PGA have a $\mathrm{p} K_{a}$ value of 3.7, and at low $\mathrm{pH}$ $(<3.7)$ the polymer adopts an $\alpha$-helix conformation that undergoes a transition to random coil conformation upon deprotonation of the acid groups at elevated $\mathrm{pH}(>3.7) .{ }^{[27]}$ Therefore, if the PLGA capsules were not cross-linked, the increase of electrostatic repulsion at high $\mathrm{pH}$ (> 3.7) would be expected to cause the capsules to swell and/or disassemble. ${ }^{[5,27]}$ However, when the PLGA capsules were exposed to the buffered solutions neither swelling nor disassembly were observed from DIC microscope images (Figure S6), indicating that the capsules are held together by a dense cross-linked structure. Furthermore, the PLGA capsules also remained stable upon immersion in urea solution (Figure S6), which implies that the observed mechanical stability arises from covalent cross-linking rather than non-covalent hydrogen-bonding between the polymer chains.

The crucial involvement of labile protecting groups (e.g., benzyl esters) in the cross-chain termination reactions and stable capsule formation was investigated by conducting the polymerisation with different amino acid NCA derivatives, including benzyl-L-aspartate NCA (Asp-NCA) and $\varepsilon$-carboxybenzyloxy-L-lysine NCA (Lys-NCA). If cross-chain termination reactions are responsible for stable capsule formation, polymerisation of Asp-NCA (which has a labile benzyl ester protecting group) to generate poly(benzyl-L-aspartate) (PBLA) grafts should lead to capsule formation due to the proposed cross-chain termination reactions. As predicted, after polymerisations with Asp-NCA for $24 \mathrm{~h}$ using an initial monomer concentration of $200 \mathrm{mg} / \mathrm{mL}$, DIC microscopy and AFM images revealed the formation of stable poly(L-aspartic acid) (PLAA) capsules (after deprotection of the remaining benzyl protecting groups of the grafted PBLA and template dissolution) with a single wall thickness 
of $45 \pm 5.0 \mathrm{~nm}$ (Figure S7). In comparison, Lys-NCA has a benzyl carbamate protecting group that is not susceptible to nucleophilic attack under the reaction conditions employed (24h, initial Lys-NCA concentration of $200 \mathrm{mg} / \mathrm{mL}$ ) and therefore, its polymerisation to afford poly( $\varepsilon$-carboxybenzyloxy-L-lysine) (PCbzLL) grafts did not result in capsule formation (Figure S7). These reactions provide convincing evidence for the role of cross-chain termination reactions in stable capsule formation.

To highlight the synergistic role of the hyperbranched PEI macroinitiator in stable PLGA capsule formation several control experiments were conducted. Firstly, Glu-NCA polymerisation was conducted using bare silica particles (without PEI adsorption); following template removal, DIC microscopy (Figure S8) revealed the absence of capsules. Secondly, the ability of the PEI alone to form capsules was investigated via deposition of PEI onto the silica substrate, followed by template dissolution, which also yielded no capsules (Figure S8). These control experiments demonstrate that the combination of both surface deposited macroinitiator and surface-initiated ROP are vital to the formation of stable polypeptide capsules. In order to investigate the effect of the polymeric macroinitiator further, other amine functionalised substrates were studied, namely (3-aminopropyl)triethoxysilane (APTS)modified silica particles. ${ }^{[27]}$ Silanisation of the silica template with APTS followed by ROP of Glu-NCA $(200 \mathrm{mg} / \mathrm{mL})$ for $96 \mathrm{~h}$ resulted in no capsule formation after deprotection and template dissolution (Figure S8). Although silanisation with APTS is commonly employed to aminate silica substrates, it is not surprising that such an initiating layer failed to afford stable capsules after ROP, as template dissolution would result in the removal the underlying initiating layer. In comparison, when PEI is employed, removal of the underlying silica template does not affect the intermeshed network of hyperbranched PEI from which the grafted polypeptide chains extend. These results imply that the use of macroinitiators with a high density of initiating amine groups (e.g., PEI) play an important role in capsule formation, 


\section{Submitted to \\ ADANECDS
MATERRALIS}

as they are capable of generating densely grafted films that have a high propensity to undergo cross-linking via cross-chain termination reactions.

The biodegradability of the cross-linked PLGA capsules was demonstrated via enzymatic degradation with papain (also known as papaya proteinase I), an endopeptidase previously reported to be suitable for degradation of PLGA-based materials. ${ }^{[29]}$ PLGA capsules isolated after $24 \mathrm{~h}$ (using an initial Glu-NCA concentration of $200 \mathrm{mg} / \mathrm{mL}$ ) were incubated in buffered solution containing the papain enzyme (refer to SI for detailed degradation conditions) at 37 ${ }^{\circ} \mathrm{C}$. To qualitatively confirm the degradability of PLGA capsules in the presence of papain, DIC microscopy images were recorded at various times after the addition of the enzyme (Figure 2). The addition of papain initially appeared to result in a slight shrinkage of the PLGA capsules (Figure 2C, $t=1 \mathrm{~h}$ ), which was followed by the collapse of capsules (Figure 2D, $t=21 \mathrm{~h}$ ) and finally, complete degradation after $40 \mathrm{~h}$ (Figure 2E).

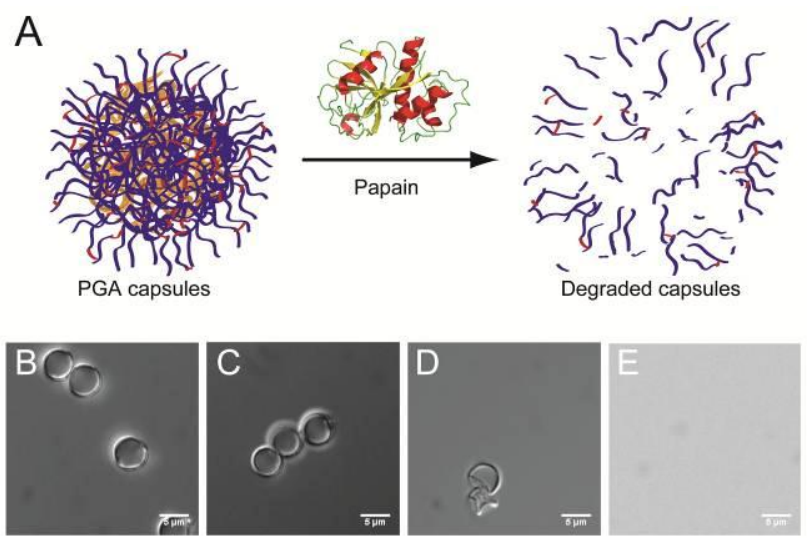

Figure 2. (A) Schematic illustration of the enzymatic degradation of PLGA capsules by papain. DIC microscopy images of PLGA capsules (B) before the addition of papain, and after (C) 1, (D) 21 and (E) $40 \mathrm{~h}$ incubation in papain solution. Scale bars are $5 \mu \mathrm{m}$.

To expand the versatility of the presented synergistic approach and demonstrate the functional tuneability of the resulting capsules, the fabrication process was repeated using a combination of amino acid NCAs, specifically Glu-NCA and Lys-NCA. Whereas, Glu-NCA will provide grafted chains with labile benzyl ester suitable for cross-chain termination to 
generate cross-linked films, the Lys-NCA component will introduce amine functionalities into the grafted films of the resulting capsules following deprotection and template dissolution (Figure 3A). Thus, the surface-initiated ROP of Glu-NCA and Lys-NCA was conducted at various Glu/Lys ratios of $0.5,1,2,4,6$ and 8, and a total initial amino acid NCA concentration of $0.76 \mathrm{M}$ (equivalent to $200 \mathrm{mg} / \mathrm{mL}$ of Glu-NCA). As discussed previously, the grafting of only Lys-NCA does not result in stable capsules formation as a result of insufficient cross-linking of the films (Figure 3B), while grafting with Glu-NCA provides mechanically stable capsules (Figure 3I). DIC microscopy images of the isolated capsules after deprotection and template dissolution revealed that stable capsules composed of random copolymers of L-glutamic acid and L-lysine (P(LGA-r-LL)) were formed when the Glu/Lys ratio was $\geq 2$ (Figures $3 \mathbf{C}-\mathbf{H}$ ). AFM analysis of capsules formed when the Glu/Lys ratio was 2, 4, 6 and 8 revealed capsules with wall thicknesses of $42 \pm 3.2,45 \pm 5.1,46 \pm 2.5$ and $45 \pm$ $1.4 \mathrm{~nm}$, respectively. The lower measured thicknesses compared to the thickness of the pure PLGA capsules (Figures 3I, $71 \pm 1.5 \mathrm{~nm}$ ) may result from the bulky side-chain of the Lys constituents shielding the propagating amino groups, causing a decrease in the overall polymerisation rate. Nevertheless, this study demonstrates that the addition of a sufficient amount of Glu-NCA (or any other NCA with a labile side group) into the system allows for efficient cross-chain termination reactions and provides facile access to stable multicomponent polypeptide capsules with tailored functionalities and properties. 


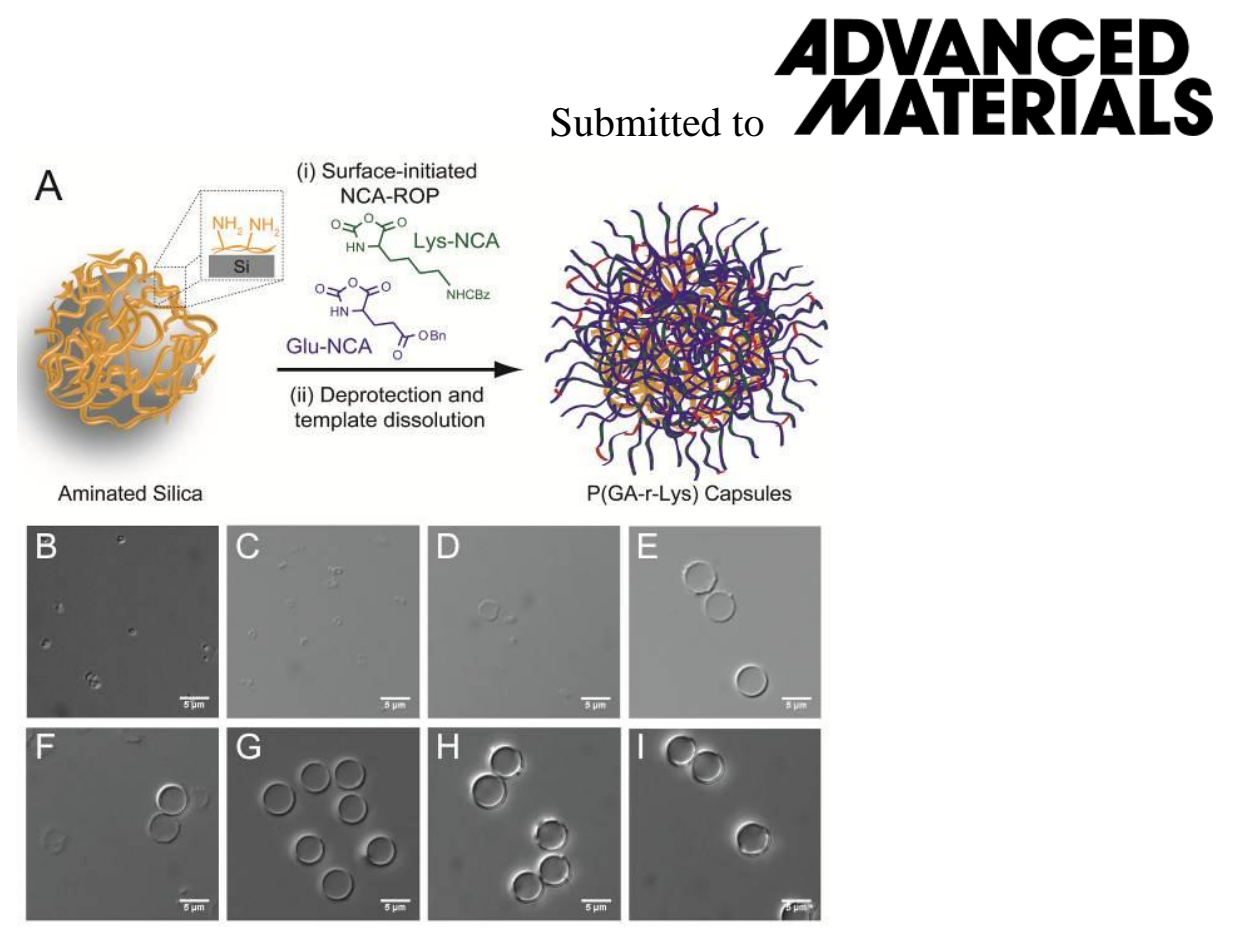

Figure 3. (A) Schematic illustration of the formation of polypeptide-based capsules composed of random copolymer grafts of L-glutamic acid and L-lysine (P(LGA-r-LL)). (B) DIC microscopy image of ill-defined products isolated after $24 \mathrm{~h}$ using an initial Lys-NCA concentration of $200 \mathrm{mg} / \mathrm{mL}$. (C-H) DIC microscopy images of capsules isolated after $24 \mathrm{~h}$ using Glu-NCA/Lys-NCA (total NCA concentration of $0.76 \mathrm{M}$ ) in ratios of $0.5,1,2,4,6$ and 8, respectively. (I) DIC microscopy image of capsules formed after $24 \mathrm{~h}$ using an initial Glu-NCA concentration of $200 \mathrm{mg} / \mathrm{mL}$. Scale bars are $5 \mu \mathrm{m}$.

In conclusion, we have presented a facile and robust method to fabricate cross-linked polypeptide-based films with tailorable thickness and composition in a single-step. Subsequent removal of the underlying silica template provides access to mechanically stable polypeptide capsules, which can be biodegraded in the presence of enzymes, making them interesting candidates for various targeted bioapplications. Central to this new assembly approach is the synergistic combination of surface deposited hyperbranched macroinitiators, surface-grafting of amino acid $\mathrm{N}$-carboxyanhydrides via ring-opening polymerisation and cross-chain termination reactions. Whereas the thickness and morphology of the capsules can be tuned by varying the polymerisation time and initial monomer concentration, the composition and functionality of the capsules can be controlled by using a combination of different amino acid NCA derivatives and amino acid NCA protected by labile benzyl ester protecting group. Studies are currently underway to investigate the formation of peptide-based capsules with tailored degradation profiles for potential applications in polymer therapeutics, 


\section{ADVANCED

catalysis and sensing devices. 
Submitted to

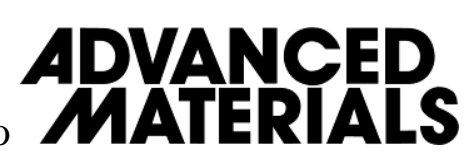

[1] A. Sulistio, A. Blencowe, J. Wang, G. Bryant, X. Zhang, G. G. Qiao, Macromol. Biosci. 2012, 12, 1220.

[2] A. Sulistio, A. Blencowe, A. Widjaya, X. Zhang, G. Qiao, Polym. Chem. 2012, 3, 224.

[3] A. Sulistio, J. Lowenthal, A. Blencowe, M. N. Bongiovanni, L. Ong, S. L. Gras, X. Zhang, G. G. Qiao, Biomacromolecules 2011, 12, 3469.

[4] A. Sulistio, A. Widjaya, A. Blencowe, X. Zhang, G. Qiao, Chem. Comm. 2011, 47, 1151.

[5] A. L. Becker, A. P. R. Johnston, F. Caruso, Small 2010, 6, 1836.

[6] G. Marcelo, A. Munoz-Bonilla, J. Rodriguez-Hernandez, M. Fernandez-Garcia, Polym. Chem. 2013, 4, 558.

[7] F. Audouin, M. Fox, R. Larragy, P. Clarke, J. Huang, B. O’Connor, A. Heise, Macromolecules 2012, 45, 6127.

[8] P. T. Hammond, Materials Today 2012, 15, 196.

[9] Y. Min, P. T. Hammond, Chem. Mat. 2011, 23, 5349.

[10] R. E. Samuel, A. Shukla, D. H. Paik, M. X. Wang, J. C. Fang, D. J. Schmidt, P. T. Hammond, Biomaterials 2011, 32, 7491.

[11] F. Caruso, H. Möhwald, J. Am. Chem. Soc. 1999, 121, 6039.

[12] C. J. Ochs, G. K. Such, Y. Yan, M. P. van Koeverden, F. Caruso, ACS Nano. 2010, 4, 1653.

[13] J. Cui, Y. Yan, G. K. Such, K. Liang, C. J. Ochs, A. Postma, F. Caruso, Biomacromolecules 2012, 13, 2225.

[14] C. J. Ochs, T. Hong, G. K. Such, J. Cui, A. Postma, F. Caruso, Chem. Mat. 2011, 23, 3141 .

[15] Y.-C. Chang, C. W. Frank, Langmuir 1996, 12, 5824

[16] M. Kar, B. Malvi, A. Das, S. Panneri, S. S. Gupta, J. Mat. Chem. 2011, 21, 6690.

[17] M. Kar, M. Pauline, K. Sharma, G. Kumaraswamy, S. Sen Gupta, Langmuir 2011, 27, 12124.

[18] M. Kar, P. S. Vijayakumar, B. L. V. Prasad, S. S. Gupta, Langmuir 2010, 26, 5772.

[19] B. Fong, P. S. Russo, Langmuir 1999, 15, 4421.

[20] S. S. Balamurugan, E. Soto-Cantu, R. Cueto, P. S. Russo, Macromolecules 2009, 43, 62.

[21] E. Soto-Cantu, S. Turksen-Selcuk, J. Qiu, Z. Zhou, P. S. Russo, M. C. Henk, Langmuir 2010, 26, 15604.

[22] P. D. Thornton, A. Heise, J. Am. Chem. Soc. 2010, 132, 2024. 
[23] R. H. Wieringa, A. J. Schouten, Macromolecules 1996, 29, 3032.

[24] R. H. Wieringa, E. A. Siesling, P. F. M. Geurts, P. J. Werkman, E. J. Vorenkamp, V. Erb, M. Stamm, A. J. Schouten, Langmuir 2001, 17, 6477.

[25] R. H. Wieringa, E. A. Siesling, P. J. Werkman, H. J. Angerman, E. J. Vorenkamp, A. J. Schouten, Langmuir 2001, 17, 6485.

[26] R. H. Wieringa, E. A. Siesling, P. J. Werkman, E. J. Vorenkamp, A. J. Schouten, Langmuir 2001, 17, 6491.

[27] T. Borase, M. Iacono, S. I. Ali, P. D. Thornton, A. Heise, Polym. Chem. 2012, 3, 1267.

[28] G. J. M. Habraken, M. Peeters, C. H. J. T. Dietz, C. E. Koning, A. Heise, Polym. Chem. 2010, 1, 514.

[29] W. G. Miller, J. Am. Chem. Soc. 1961, 83, 259. 


\section{Experimental Section}

PLGA capsule fabrication: Silica particles $(5.0 \pm 0.2 \mu \mathrm{m}, 1.0 \mathrm{wt} \%$ solution $)$ were washed with deionised water $(2 \times 1 \mathrm{~mL})$ and then exposed to a PEI solution $(1 \mathrm{~mL}, 1 \mathrm{mg} / \mathrm{mL}$ in $0.5 \mathrm{M}$ $\mathrm{NaCl}$ buffer) with continuous agitation at $20{ }^{\circ} \mathrm{C}$ for $30 \mathrm{~min}$. Subsequently, the particles were thoroughly washed with deionised water $(3 \times 1 \mathrm{~mL})$, anhydrous THF $(3 \times 1 \mathrm{~mL})$ and anhydrous DMF $(3 \times 1 \mathrm{~mL})$ to remove unbound PEI. The aminated silica particles were then added to a solution of benzyl-L-glutamate NCA (Glu-NCA) $(1 \mathrm{~mL}, 200 \mathrm{mg} / \mathrm{mL}, 0.76 \mathrm{M}$ in anhydrous DMF). After a predetermined period of time, the PBLG-coated silica particles were washed with DMF $(3 \times 1 \mathrm{~mL})$ and deionised water $(3 \times 1 \mathrm{~mL})$ before deprotection in $\mathrm{HBr}$ and core dissolution in buffered $2 \mathrm{M} \mathrm{HF} / 8 \mathrm{M} \mathrm{NH}_{4} \mathrm{~F}$ ( $\mathrm{pH}$ 5.0) solution to afford poly(Lglutamic acid) (PLGA) capsules. Refer to SI for detailed experimental and characterisation procedures.

\section{Acknowledgements}

The authors acknowledge the Australian Research Council under the Australian Laureate Fellowship (FL120100030, F.C.), Future Fellowship (FT110100411, G.G.Q.) and Discovery Project (DP130101846, F.C., G.G.Q.) schemes for financial support of this work.

\section{Supporting Information}

Supporting Information is available online from Wiley InterScience or from the author.

Received: ((will be filled in by the editorial staff))

Revised: ((will be filled in by the editorial staff)) Published online: ((will be filled in by the editorial staff)) 
The table of contents entry

Cross-linked polypeptide-based films were fabricated via a novel and robust method employing surface-initiated ring opening polymerization of $\alpha$-amino acid $N$ carboxyanhydrides (NCA-ROP). The judicious combination of amine-based hyperbranched macroinitiators and benzyl ester-protected NCA derivatives promotes network formation by cross-chain terminations, which allows the formation of free-standing peptide-based capsules in a single-step and one-pot system. Furthermore, the chemical and physical properties of the capsules can be readily tuned by variation of the polymerisation time, monomer concentration and monomer composition, while maintaining enzymatic degradability.

Keyword (see list on page 1)

Steven Harris Wibowo, Edgar H. H. Wong, Adrian Sulistio, Stefanie N. Guntari, Anton Blencowe, Frank Caruso*, and Greg G. Qiao*

Assembly of free-standing polypeptide films via the synergistic combination of hyperbranched macroinitiators, the grafting-from approach and crosschain termination.

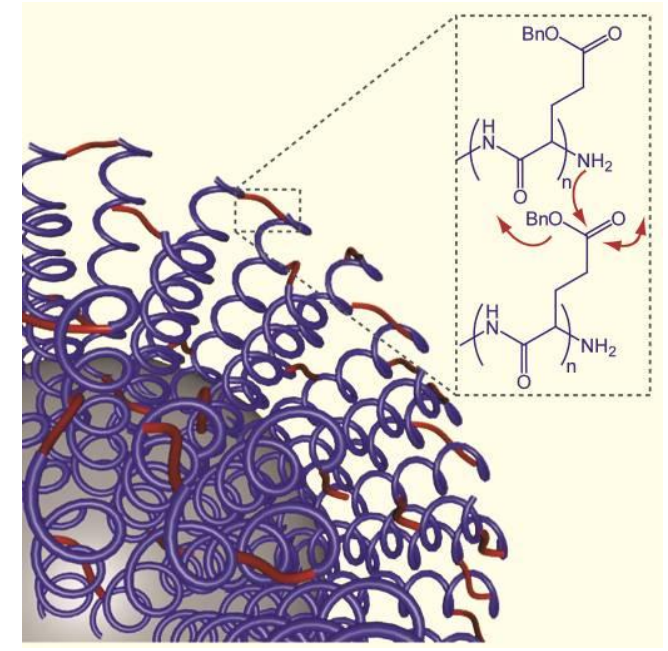

ToC figure 


\section{Supporting Information}

Assembly of free-standing polypeptide films via the synergistic combination of hyperbranched macroinitiators, the grafting-from approach and crosschain termination.

By Steven Harris Wibowo, Edgar H.H. Wong, Adrian Sulistio, Stefanie N. Guntari, Anton Blencowe, Frank Caruso, ${ }^{*}$ and Greg G. Qiao*

[*] Department of Chemical and Biomolecular Engineering The University of Melbourne Parkville, VIC 3010, Australia

Email: greghq@unimelb.edu.au ,fcaruso@unimelb.edu.au 


\section{Materials}

Submitted to

\section{ADVANCEP}

H-Glu(OBzl)-OH, H-Asp(OBzl)-OH and H-Lys(Z)-OH were obtained from Bachem and used as received. Hyperbranched poly(ethyleneimine) (PEI) $\left(M_{\mathrm{W}} \sim 25 \mathrm{kDa}, 50 \mathrm{wt} \%\right.$ in $\left.\mathrm{H}_{2} \mathrm{O}\right)$, triphosgene (98\%), (3-aminopropyl)triethoxysilane (APTS) (98\%), hydrofluoric acid (48 wt $\%$ in $\mathrm{H}_{2} \mathrm{O}$ ), $n$-pentane (anhydrous, > $99 \%$ ), hydrobromic acid (33\% in acetic acid), Lcysteine (> $97 \%)$, ethylenediaminetetraacetate (EDTA) (> $99 \%)$, lyophilised papain from papaya latex (12 units/mg, $70 \%$ protein) and potassium trifluoroacetate (KTFA) (98\%) were purchased from Aldrich and used as received. Ammonium fluoride (Fluka, $40 \%$ in $\mathrm{H}_{2} \mathrm{O}$ ), trans-2-[3-(4-tert-butylphenyl)-2-methyl-2-propenylidene] malononitrile (DCTB) (Santa Cruz Biotechnology, > $99 \%$ ), anhydrous $N, N$-dimethylformamide (DMF) (Acros Organics, extra dry, > $99.8 \%$ ), tetrahydrofuran (THF) (Honeywell, $99.9 \%$, HPLC grade) and sulphuric acid $\left(\mathrm{H}_{2} \mathrm{SO}_{4}\right)$ (Scharlau, $\left.99 \%\right)$ were used as received. $n$-Hexane $(99 \%)$, sodium chloride $(\mathrm{NaCl})$ (99 \%), hydrogen peroxide $\left(\mathrm{H}_{2} \mathrm{O}_{2}\right) \quad(30 \%)$, isopropanol (IPA) (99 \%), $N, N$ dimethylformamide (DMF) (98\%) and methanol (98\%) were purchased from Chem-Supply and used as received. Anhydrous and deoxygenated THF was obtained by distillation under argon from sodium benzophenone ketyl. Deuterated dimethylsulfoxide ( $d_{6}$-DMSO) was purchased from Cambridge Isotope Laboratories and was used as received. High-purity water (Milli Q) with a resistivity greater than $18 \mathrm{M} \Omega . \mathrm{cm}$ was obtained from an in-line Millipore RiOs/Origin water purification system.

Nonporous silica particles (5 wt\% suspensions, average diameter $5.0 \pm 0.2 \mu \mathrm{m}$ ) were purchased from Microparticles GmbH (Berlin, Germany). Silicon wafers (MMRC Pty. Ltd., Melbourne, Australia) were cut into $c a .1 \times 1 \mathrm{~cm}$ squares and cleaned with Piranha solution (sulphuric acid: hydrogen peroxide $=7: 3$ ) - caution! Piranha solution is highly corrosive and extreme care should be taken during preparation and use. The wafers were then sonicated in isopropanol:water (1:1) solution for $20 \mathrm{~min}$ followed by soaking in RCA solution (water: 
ammonia: hydrogen peroxide $=5: 1: 1)$ for another $20 \mathrm{~min}$ at $60{ }^{\circ} \mathrm{C}$. The wafers were thoroughly washed with Milli Q after each step.

\section{Characterisation Methods}

Proton $\left({ }^{1} \mathrm{H}\right)$ nuclear magnetic resonance (NMR) spectroscopy was conducted using a Varian Unity $400 \mathrm{MHz}$ spectrometer operating at $400 \mathrm{MHz}$, using deuterated dimethyl sulfoxide ( $d_{6^{-}}$ DMSO) with a sample concentration of approximately $20 \mathrm{mg} / \mathrm{mL}$.

Differential interference contrast (DIC) microscopy images of polypeptide coated particles and polypeptide capsules were taken with an Olympus IX71 digital wide-field inverted microscope equipped with DIC slider (U-DICT, Olympus), a 60x oil immersion objective (Olympus UPFL20/0.5NA, W.D. 1.6), a UF1032 fluorescence filter cube and the corresponding filter sets. A CCD camera was mounted on the left-hand port of the microscope and a tungsten lamp was used for DIC images.

Atomic force microscopy (AFM) images were acquired with a MFP-3D Asylum Research instrument. Scans were conducted in AC mode with ultrasharp SiN gold-coated cantilevers purchased from MikroMasch (Bulgaria). Image processing was then performed using the Nanoscope and IgorPro software packages. For AFM measurements, $1 \mu \mathrm{L}$ of a concentrated capsule solution was placed on a PEI coated silicon wafer and allowed to air dry. The thickness measured by AFM corresponds to double-wall thickness and was therefore halved to obtain the single-wall thickness of the capsules. The reported thicknesses are an average of at least 10 measurments on seperate capsules. 
MALDI ToF mass spectra were acquired on a Bruker Autoflex III Mass Spectrometer operating in positive/linear mode, using DCTB and KTFA as the matrix and cationisation agent, respectively. DCTB and KTFA were dissolved in THF to afford solutions with concentrations of $40 \mathrm{mg} / \mathrm{mL}$ and $5 \mathrm{mg} / \mathrm{mL}$, respectively, and were then mixed with the analyte solution at a volumetric ratio of 10:1:0.1. Subsequently, $0.2 \mu \mathrm{L}$ of this solution was spotted onto a ground steel target plate and allowed to air dry at room temperature before analysis. Analysis of the spectra was performed using FlexAnalysis (Bruker) software. For verification purposes the analysis was also conducted with NaTFA in place of KTFA, under identical conditions.

\section{Experimental Methods}

\section{Synthesis of Benzyl-L-glutamate NCA (Glu-NCA)}

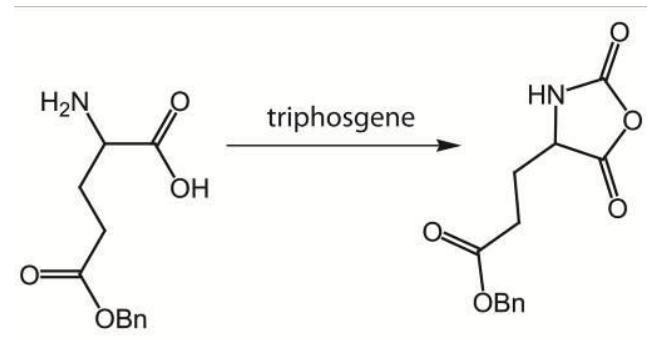

H-Glu(OBzl)-OH (1.00 g, $4.21 \mathrm{mmol})$ was suspended in anhydrous THF (20 mL) under argon and triphosgene $(0.50 \mathrm{~g}, 1.70 \mathrm{mmol})$ was added. The reaction was stirred at $60{ }^{\circ} \mathrm{C}$ until a homogeneous solution was obtained $(c a .1 \mathrm{~h})$. The reaction mixture was cooled to room temperature, bubbled with argon to remove unreacted phosgene and $\mathrm{HCl}$, and concentrated in vacuo. The resulting residue was then recrystallised from 1:1.5 anhydrous THF:hexane (20 $\mathrm{mL}) 3$ times, washed with anhydrous n-pentane $(50 \mathrm{~mL})$ and dried in vacuo to afford GluNCA as colourless crystals, $0.87 \mathrm{~g}(79 \%) .{ }^{1} \mathrm{H}$ NMR (400 MHz, $d_{6}$-DMSO): $\delta_{\mathrm{H}} 1.87-2.10(m$, $\left.2 \mathrm{H}, \mathrm{CH}_{2}\right), 2.52\left(t, 2 \mathrm{H}, J=7.6 \mathrm{~Hz}, \mathrm{CH}_{2}\right), 4.45(d d, 1 \mathrm{H}, J=5.6 \& 8.0 \mathrm{~Hz}, \mathrm{CHN}), 5.10(s, 2 \mathrm{H}$, $\left.\mathrm{CH}_{2} \mathrm{O}\right), 7.31-7.40(m, 5 \mathrm{H}, \mathrm{ArH}), 9.09(s, 1 \mathrm{H}, \mathrm{NH}) \mathrm{ppm} .{ }^{13} \mathrm{C} \mathrm{NMR}\left(100 \mathrm{MHz}, d_{6}\right.$-DMSO): $\delta_{\mathrm{C}}$ 
$26.3\left(\mathrm{CH}_{2}\right), 29.0\left(\mathbf{C H}_{2}\right), 56.1(\mathbf{C H N}), 65.6\left(\mathbf{C H}_{2}\right), 127.9(3 \mathrm{ArCH}), 128.4(2 \mathrm{ArCH}), 135.9$ (ArCC), $151.8\left(\mathrm{NHCO}_{2}\right), 171.2\left(\mathrm{CHCO}_{2}\right), 171.6\left(\mathrm{CH}_{2} \mathrm{CO}_{2}\right) \mathrm{ppm}$.

\section{Synthesis of Benzyl-L-Aspartate NCA (Asp-NCA)}

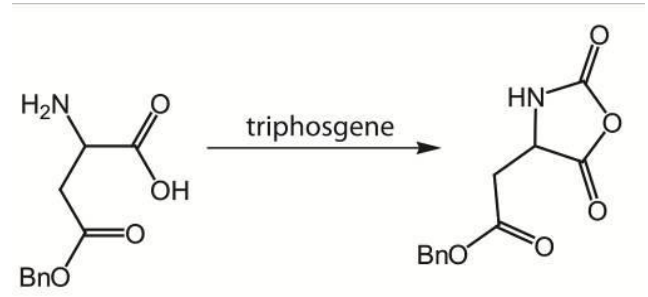

H-Asp(OBzl)-OH (0.50 g, $2.23 \mathrm{mmol})$ was suspended in anhydrous THF (10 mL) under argon and triphosgene $(0.26 \mathrm{~g}, 0.88 \mathrm{mmol})$ was added. The reaction was stirred at $60{ }^{\circ} \mathrm{C}$ until a homogeneous solution was obtained $(c a .1 \mathrm{~h})$. The reaction mixture was cooled to room temperature, bubbled with argon to remove unreacted phosgene and $\mathrm{HCl}$, and concentrated in vacuo. The resulting residue was then redissolved in the minimum amount of anhydrous THF (ca. $5 \mathrm{~mL}$ ) and precipitated into anhydrous pentane $(50 \mathrm{~mL})$. The precipitate was collected via centrifugation and dried in vacuo to afford Asp-NCA as colourless crystals, $0.45 \mathrm{~g}(81 \%) .{ }^{1} \mathrm{H}$ NMR (400 MHz, $d_{6}$-DMSO): $\delta_{\mathrm{H}} 2.83-3.07\left(m, 2 \mathrm{H}, \mathrm{CH}_{2}\right), 4.67(d d, 1 \mathrm{H}, J=5.6 \& 8.0 \mathrm{~Hz}$, $\mathrm{CHN}), 5.10\left(s, 2 \mathrm{H}, \mathrm{CH}_{2} \mathrm{O}\right), 7.32-7.40(m, 5 \mathrm{H}, \mathrm{ArH}), 8.95(s, 1 \mathrm{H}, \mathrm{NH}) \mathrm{ppm} .{ }^{13} \mathrm{C}$ NMR $(100$ $\mathrm{MHz}, d_{6}$-DMSO): $\delta_{\mathrm{C}} 34.7\left(\mathrm{CH}_{2} \mathrm{CH}\right), 53.6(\mathbf{C H}), 66.3\left(\mathrm{CH}_{2} \mathrm{Ar}\right), 128.1-128.2(3 \mathrm{ArCH}), 128.5$ (2 $\mathrm{ArCH}), 135.4(\mathrm{ArCC}), 152.1(\mathrm{C}(\mathrm{O}) \mathrm{NH}), 169.3\left(\mathrm{OC}(\mathrm{O}) \mathrm{CH}_{2}\right), 171.0(\mathrm{OC}(\mathrm{O}) \mathrm{CH}) \mathrm{ppm}$.

\section{Synthesis of ع-Carbobenzyloxy-L-Lysine NCA (Lys-NCA)}

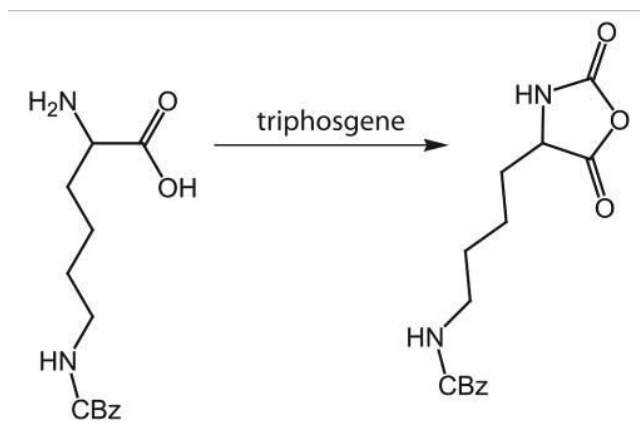


H-Lys(CBz)-OH (0.50 g, $1.78 \mathrm{mmol})$ was suspended in anhydrous THF (10 mL) under argon and triphosgene $(0.21 \mathrm{~g}, 0.70 \mathrm{mmol})$ was added. The reaction was stirred at $60{ }^{\circ} \mathrm{C}$ until a homogeneous solution was obtained $(c a .1 \mathrm{~h})$. The reaction mixture was cooled to room temperature, bubbled with argon to remove unreacted phosgene and $\mathrm{HCl}$, and concentrated in vacuo.The resulting residue was then recrystallised from 2:3 anhydrous THF:hexane (100 mL) 3 times, washed with anhydrous n-pentane $(20 \mathrm{~mL})$ and dried in vacuo to afford LysNCA as colourless crystals $(0.40 \mathrm{~g}, 73 \%) .{ }^{1} \mathrm{H}$ NMR (400 MHz, $d_{6}$-DMSO): $\delta_{\mathrm{H}} 1.22-1.45$ (m, 4H, $\left.2 \mathrm{CH}_{2}\right), 1.60-1.77\left(m, 2 \mathrm{H}, 1 \mathrm{CH}_{2}\right), 3.01\left(q, 2 \mathrm{H}, J=6.0 \mathrm{~Hz}, \mathrm{CH}_{2} \mathrm{~N}\right), 4.42(t, 1 \mathrm{H}, J=6.0$ $\mathrm{Hz}, \mathrm{CHN}), 5.00\left(s, 2 \mathrm{H}, \mathrm{CH}_{2} \mathrm{O}\right), 7.25-7.38(m, 5 \mathrm{H}, 5 \mathrm{ArH}), 9.09$ (br s, 2H, $\left.2 \mathrm{NH}\right) \mathrm{ppm} .{ }^{13} \mathrm{C}$ NMR (100 MHz, $d_{6}$-DMSO): $\delta_{\mathrm{C}} 21.5\left(\mathbf{C H}_{2}\right), 28.7\left(\mathbf{C H}_{2}\right), 30.6\left(\mathbf{C H}_{2}\right), 56.9(\mathbf{C H N}), 65.0$ $\left(\mathrm{CH}_{2} \mathrm{~N}\right), 127.6(3 \mathrm{ArCH}), 128.2(2 \mathrm{ArCH}), 137.1(\mathrm{ArCC}), 151.8\left(\mathrm{NHCO}_{2}\right), 156.0\left(\mathrm{NHCO}_{2}\right)$, $171.5\left(\mathrm{CHCO}_{2}\right) \mathrm{ppm}$.

\section{Silica Particle Amination by Poly(ethyleneimine)(PEI) Deposition}

Non-porous silica particles $(5.0 \pm 0.2 \mu \mathrm{m})$ were amine-functionalised via the deposition of PEI. A suspension of particles $(1 \mathrm{~mL}, 1.0 \mathrm{wt} \%)$ were transferred to a safe-lock Eppendorf tube and washed with Milli Q water $(2 \times 1 \mathrm{~mL})$. The particles were subjected to $2 \mathrm{~min}$ of centrifugation (3300 rcf) in between washing steps. PEI solution $(1 \mathrm{~mL}, 1 \mathrm{mg} / \mathrm{mL}$ in $0.5 \mathrm{M}$ $\mathrm{NaCl}$ solution) was then added to the particles and agitated at $20^{\circ} \mathrm{C}$ for $30 \mathrm{~min}$. Subsequently, the particles were thoroughly washed with Milli Q water $(3 \times 1 \mathrm{~mL})$, anhydrous THF $(3 \times 1$ $\mathrm{mL})$ and anhydrous DMF $(3 \times 1 \mathrm{~mL})$ to remove unbounded PEI. The particles were stored in anhydrous DMF (1 mL) until further use. 


\section{Submitted to

Silica Particle Amination by Silanisation with (3-aminopropyl)triethoxysilane (APTS)

Amine-functionalised particles were prepared using an APTS silanisation method reported in the literature. ${ }^{[27]}$ Following silanisation, the aminated particles were thoroughly washed with Milli Q water $(3 \times 1 \mathrm{~mL})$, anhydrous THF $(3 \times 1 \mathrm{~mL})$ and anhydrous DMF $(3 \times 1 \mathrm{~mL})$. The particles were subjected to 2 min of centrifugation (3300 rcf) in between washing steps. The particles were stored in anhydrous DMF $(1 \mathrm{~mL})$ until further use.

\section{Synthesis of Poly(L-glutamic acid) (PLGA) Capsules}

A suspension of aminated particles ( $1 \mathrm{~mL}, 1.0 \mathrm{wt} \%$ in anhydrous DMF) were centrifuged (3300 rcf) and the solvent removed prior to the addition of Glu-NCA monomer solutions (1 $\mathrm{mL}$ ) of known concentration (ranging from $20 \mathrm{mg} / \mathrm{mL}$ to $200 \mathrm{mg} / \mathrm{mL}$ in anhydrous $\mathrm{DMF}$ ). The tubes were sealed and the particles suspended at $20^{\circ} \mathrm{C}$ with constant agitation for a specified period of time ranging from 3 to $96 \mathrm{~h}$. After a specific reaction period the supernatant was removed and the PBG-coated particles were washed with DMF $(3 \times 1 \mathrm{~mL})$ and Milli Q water $(3 \times 1 \mathrm{~mL})$. The supernatant was analysed by MALDI-ToF MS. Deprotection of the remaining benzyl protecting groups was performed by the addition of $\mathrm{HBr}$ solution (300 $\mu \mathrm{L}, 33 \%$ in acetic acid) to the PBG-coated particles, followed by continuous agitation for $12 \mathrm{~h}$. Excess $\mathrm{HBr}$ and benzyl alcohol were then removed by washing with Milli Q water $(3 \times 1 \mathrm{~mL})$ to afford PLGA-coated particles. The silica templates were then removed by the addition of $100 \mu \mathrm{L}$ of $2 \mathrm{M} \mathrm{HF} / 8 \mathrm{M} \mathrm{NH}_{4} \mathrm{~F}$ solution (pH 5.0). After 2 min, the PLGA capsules were washed with Milli Q water $(3 \times 1 \mathrm{~mL})$ and then stored in Milli Q water $(1 \mathrm{~mL})$ prior to DIC microscopy and AFM.

\section{Reinitiation Reaction}

PBLG-coated silica particles $(1 \mathrm{~mL}, 1.0 \mathrm{wt} \%)$ isolated after $24 \mathrm{~h}$ of ROP were washed with anhydrous DMF $(3 \times 1 \mathrm{~mL})$ to remove unreacted monomers and non-grafted materials. After 
Submitted to

centrifugation (3300 rcf), the PBLG-coated particles were charged into a fresh Glu-NCA solution $(1 \mathrm{~mL}, 200 \mathrm{mg} / \mathrm{mL}$ in anhydrous DMF) and allowed to react for another $24 \mathrm{~h}$, followed by thorough washing with DMF $(3 \times 1 \mathrm{~mL})$ and Milli Q water $(3 \times 1 \mathrm{~mL})$. The deprotection reaction and $\mathrm{HF}$ treatment were then performed as previously described.

\section{Synthesis of Poly(L-lysine) (PLL) and Poly(L-aspartic acid) (PLAA) Capsules}

PLL and PLAA capsules were synthesised in an identical fashion to that described for the PLGA capsules, using Lys-NCA and Asp-NCA $(200 \mathrm{mg} / \mathrm{mL})$ for a reaction period of $24 \mathrm{~h}$ prior to washing, deprotection and template dissolution.

\section{Synthesis of Poly(L-glutamic acid-ran-L-lysine) (P(LGA-r-LL)) Capsules}

Silica particles aminated by the adsorption of PEI were employed to prepare P(LGA-r-LL) capsules. The P(LGA-r-LL) capsules were synthesised in an identical fasion to that described for the PLGA capsules, using a mixture of Glu-NCA and Lys-NCA at specified ratios ranging from 0.5 to 8 . The initial total NCA concentration was maintained at $0.76 \mathrm{M}$ (equivalent to $200 \mathrm{mg} / \mathrm{mL}$ of Glu-NCA when no Lys-NCA monomer was co-added).

\section{PLGA Capsule Stability Studies}

For the stability studies, PLGA capsules were washed and resuspended in various buffer solutions, including pH 4.0 (50 mM NaOAc), pH 7.0 (Milli Q water), pH 8.4 (10 mM TRIS) and $\mathrm{pH} 11.2\left(50 \mathrm{mM} \mathrm{Na} \mathrm{CO}_{3}\right)$ buffer solutions, and $20 \mathrm{mg} / \mathrm{mL}$ urea solution. DIC microscopy was then conducted to verify the stability of the PLGA capsules under these conditions.

\section{Enzymatic Degradation by Papain}

Lyophilised papain (from papaya latex, stored at $-80{ }^{\circ} \mathrm{C}$ ) was thawed at $0{ }^{\circ} \mathrm{C}$ before dissolution in $\mathrm{pH} 5.1$ acetate buffer $(0.2 \mathrm{M} \mathrm{NaCl}$ solution doped with $1 \mathrm{mM}$ EDTA and $5 \mathrm{mM}$ 


\section{Submitted to

L-cysteine) at $0{ }^{\circ} \mathrm{C}$ to afford an enzyme stock solution $(0.25 \mathrm{mg} / \mathrm{mL})$. PLGA capsules prepared at a Glu-NCA concentration of $200 \mathrm{mg} / \mathrm{mL}$ and a reaction period of $24 \mathrm{~h}$ were washed thoroughly with the same acetate buffer solution used to prepare the enzyme solution. The enzyme stock solution was warmed to $37^{\circ} \mathrm{C}$ over $c a .5 \mathrm{~min}$ and $300 \mu \mathrm{L}$ was added to the washed capsules. The capsules were then incubated at $37{ }^{\circ} \mathrm{C}$ and aliquots were taken after specified periods of time for observation via DIC microscopy. 


\section{Supporting Figures}
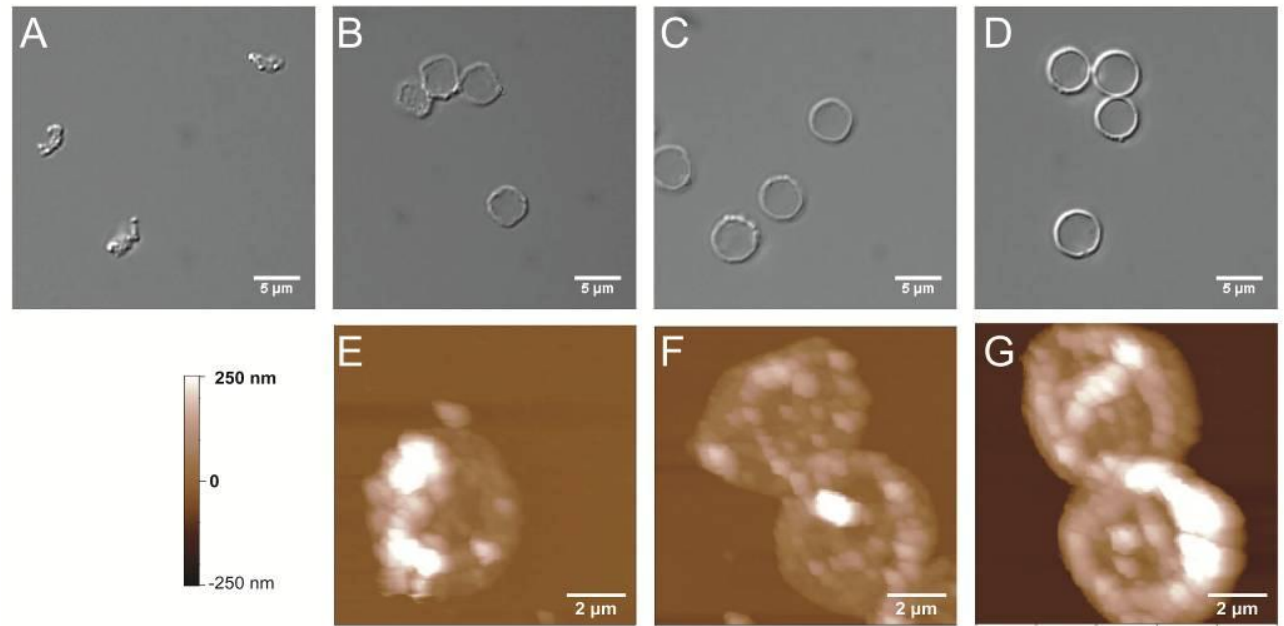

Figure S1. DIC microscopy images of PLGA capsules formed after $96 \mathrm{~h}$ at initial Glu-NCA concentrations of (A) 20, (B) 50, (C) 100 and (D) $200 \mathrm{mg} / \mathrm{mL}$. (E-G) AFM images of PLGA capsules formed at initial Glu-NCA concentrations of (E) 50, (F) 100 and (G) $200 \mathrm{mg} / \mathrm{mL}$. Scale bars are $5 \mu \mathrm{m}$ for DIC microscopy images and $2 \mu \mathrm{m}$ for AFM images.

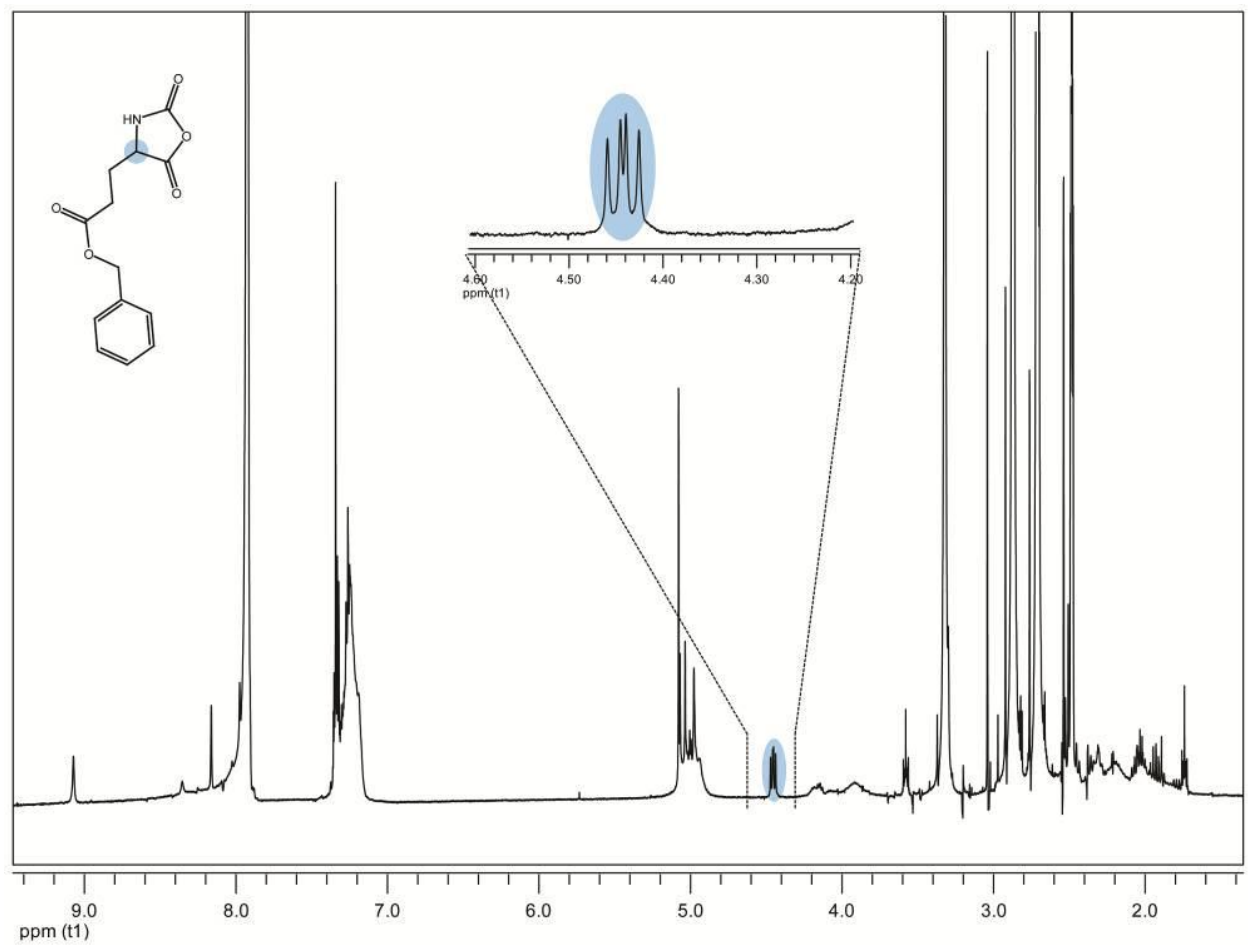

Figure S2. ${ }^{1} \mathrm{H}-\mathrm{NMR}$ spectrum of reaction supernatant after $24 \mathrm{~h}$. The resonances at $\delta_{\mathrm{H}} 4.44 \mathrm{ppm}$ corresponds to the methine proton of the unreacted Glu-NCA. 


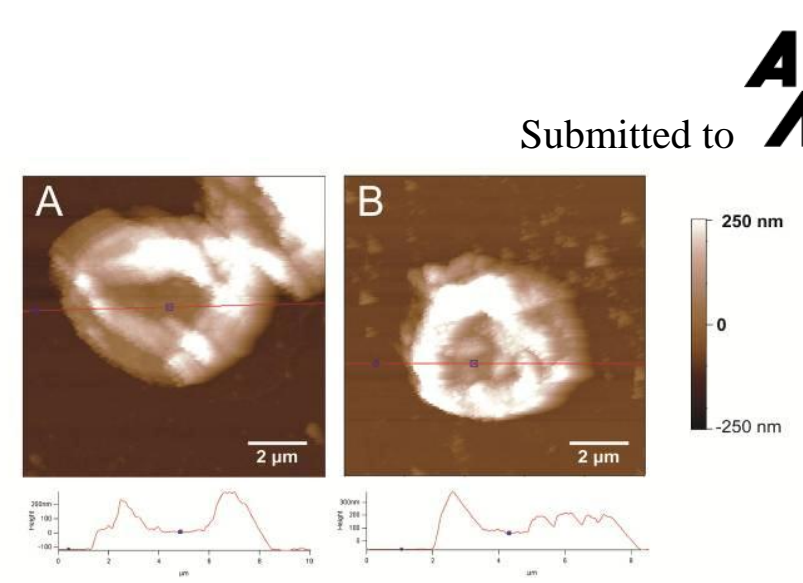

Figure S3. AFM height profile and images of PGA capsules formed (A) before and (B) after chain extension with fresh GluNCA. Scale bars are $2 \mu \mathrm{m}$. 


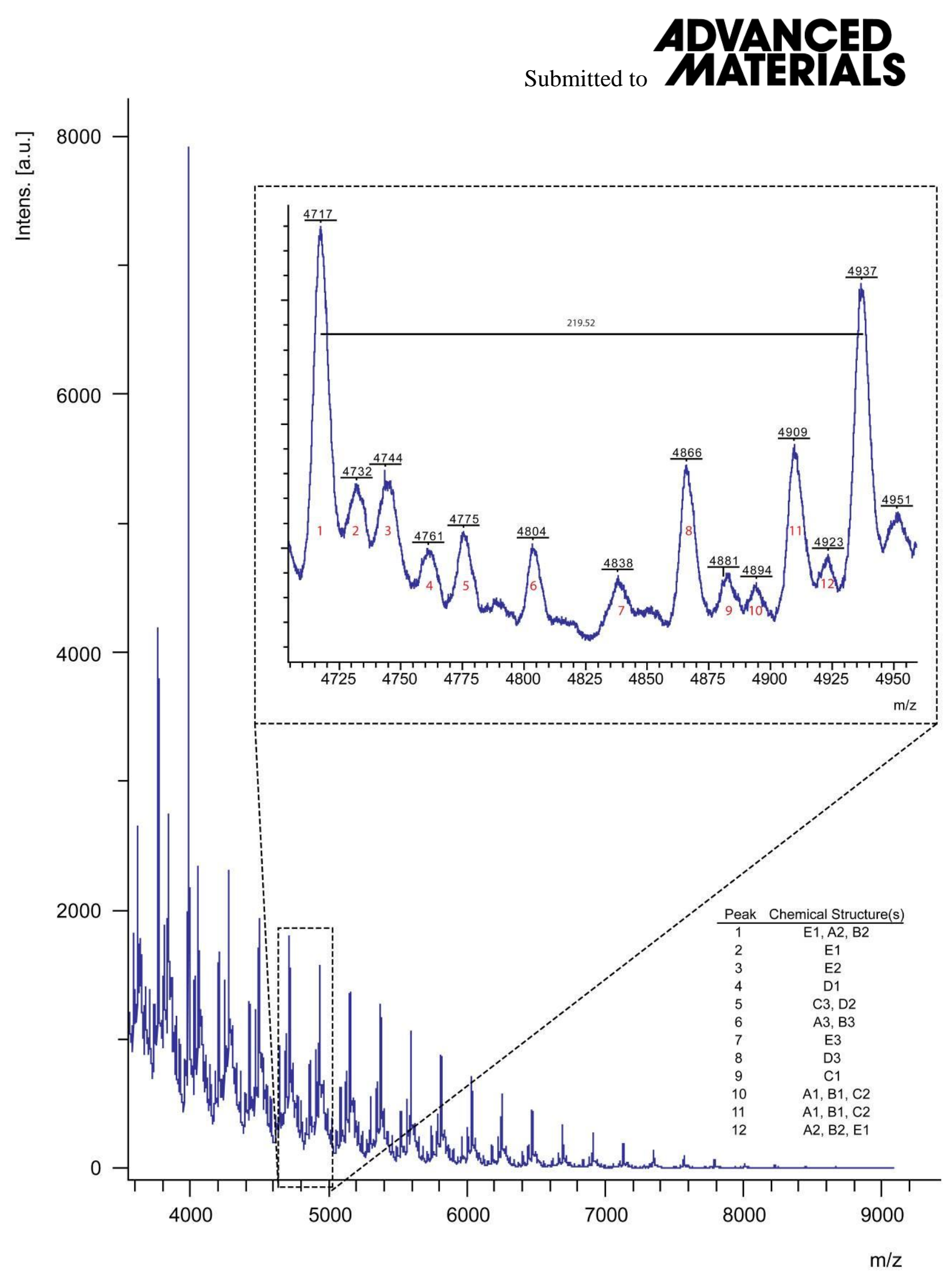

Figure S4. MALDI ToF mass spectra of the reaction supernatant obtained after the surface-initiated polymerisation of GluNCA $(200 \mathrm{mg} / \mathrm{mL})$ from PEI coated silica particles. The spectrum was acquired using linear/positive mode and DCTB and KTFA as the matrix and cationisation agent, respectively. The potential chemical structure(s) of the 12 identified series (refer to inset and table) are presented in Figure S4. 


\section{ADYANCED
MATERALAS}

A1

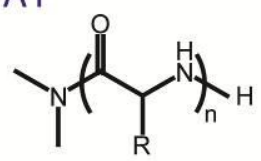

A2

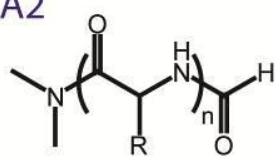

A3

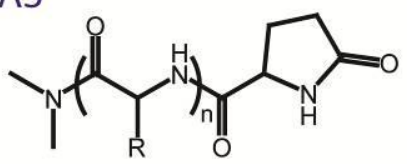

B1

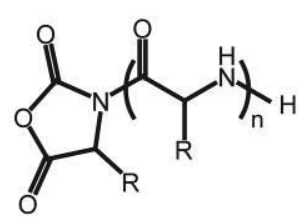

B2

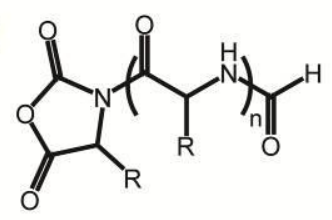

B3

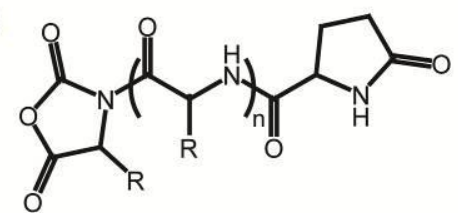

C1<smiles>[R]C(NC)C(C)=O</smiles>

C2

C3

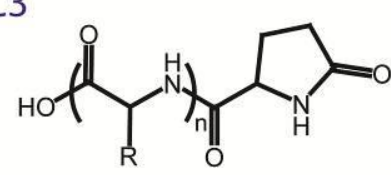

D1<smiles>[R]C(NC)C(=O)OCc1ccccc1</smiles>

D2<smiles>[R]C(NC(C)=O)C(=O)OCc1ccccc1</smiles>

D3<smiles>[R]C(NC(=O)C1CCC(=O)N1)C(=O)OCc1ccccc1</smiles>

E3<smiles>CCCC(C)C(C)C(C)C(C)C(C)C</smiles>

E1<smiles>CC(C)(C)C(C)(C)C</smiles>

E2<smiles>CC(C)(C)C(C)(C)C(C)(C)C</smiles>

$\mathrm{R}:\left(\mathrm{CH}_{2}\right)_{2} \mathrm{COOBn}$

S5. Structures of various end-group functionalised poly(benzyl-L-glutamate) identified by MALDI ToF MS (stereochemsitry not shown). 


\section{Submitted to \\ ADVANCED}
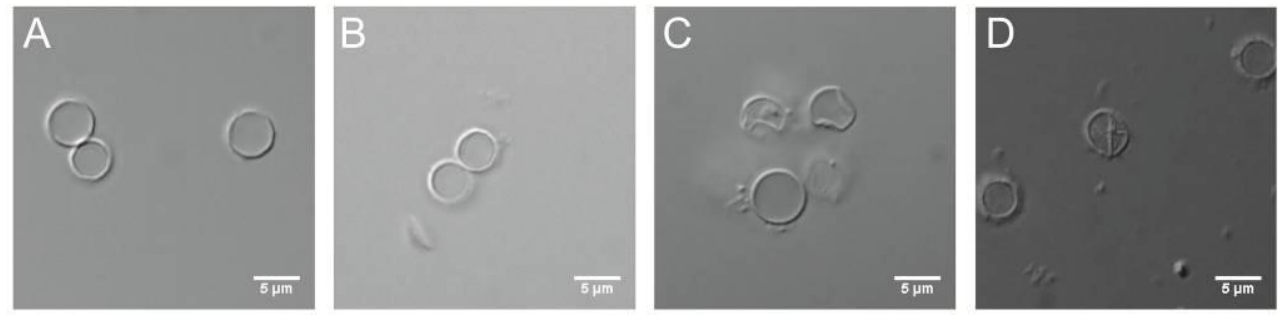

Figure S6. DIC microscopy images of PLGA capsules at pH (A) 4.0, (B) 8.0 and (C) 11.0, and in (D) urea solution (20 $\mathrm{mg} / \mathrm{mL}$ ). Scale bars are $5 \mu \mathrm{m}$.
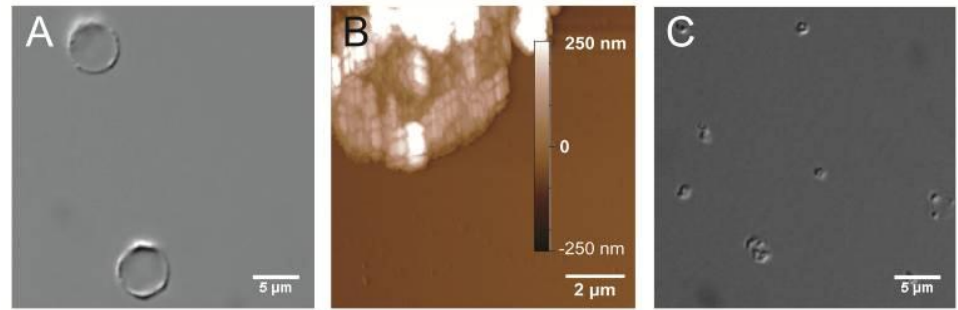

Figure S7. (A) DIC microscopy and (B) AFM images of poly(aspartic acid) (PLAA) capsules. (C) DIC microscopy image of poly(L-lysine) (PLL) capsule reminants (no capsules formed). Scale bars are $5 \mu \mathrm{m}$ for DIC images and $2 \mu \mathrm{m}$ for AFM images.
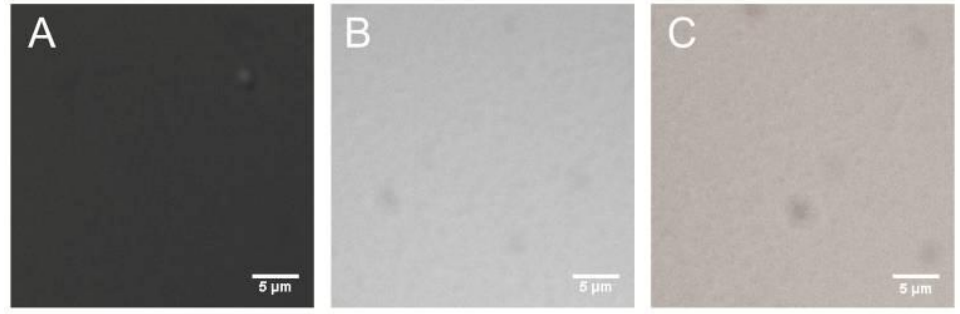

Figure S8. DIC microscopy images showing: (A) an absence of PLGA capsules when no deposition of PEI was performed (bare silica surface as initiator); (B) that immobilised PEI layer alone does not form capsules after template dissolution; (C) an absence of PLGA capsules when (3-aminopropyl)triethoxysilane (APTS)-functionalised silica particles were used as the initiator, respectively. All scale bars are $5 \mu \mathrm{m}$. 